\title{
First Report on Fusarium Wilt of Zucchini Caused by Fusarium oxysporum, in Korea
}

\author{
In-Young Choi', Ju-Hee Kim', Wang-Hyu Lee', Ji-Hyun Park ${ }^{3}$ and Hyeon-Dong Shin ${ }^{3, *}$ \\ ${ }^{1}$ Jeollabuk-do Agricultural Research and Extension Services, Iksan 570-704, Korea \\ ${ }^{2}$ Department of Agricultural Biology and Plant Medical Center, Chonbuk National University, Jeonju 561-765, Korea \\ ${ }^{3}$ Division of Environmental Science and Ecological Engineering, Korea University, Seoul 136-701, Korea
}

\begin{abstract}
Fusarium wilt of zucchini in Jeonju, Korea, was first noticed in May 2013. Symptoms included wilting of the foliage, drying and withering of older leaves, and stunting of plants. Infected plants eventually died during growth. Based on morphological characteristics and phylogenetic analyses of the molecular markers (internal transcribed spacer rDNA and translation elongation factor $1 \alpha$ ), the fungus was identified as Fusarium oxysporum. Pathogenicity of a representative isolate was demonstrated via artificial inoculation, and it satisfied Koch's postulates. To our knowledge, this is the first report of $F$. oxysporum causing wilt of zucchini in Korea.
\end{abstract}

Keywords Cucurbita pepo, Fusarium oxysporum, Fusarium wilt, Pathogenicity, Zucchini

Zucchini, Cucurbita pepo L., belonging to the family Cucurbitaceae, is a summer squash widely cultivated in many countries as a vegetable. In Korea, zucchini is cultivated in approximately 1,400 ha for domestic consumption. Several fungi have been identified that infects zucchini worldwide, such as Alternaria alternata and A. cucumerina (Alternaria leaf spot), Pseudoperonospora cubensis (downy mildew), Podosphaera xanthii (powdery mildew), Colletotrichum orbiculare (anthracnose), Cladosporium cucumerinum (scab or gummosis), Septoria cucurbitacearum (Septoria leaf spot), Didymella bryoniae (gummy stem blight), Macrophomina phaseolina (charcoal rot), Pythium (damping-off), Rhizoctonia (damping-off), and Fusarium (damping-off and wilt) [1]. Among these, fusarium wilt is an important infection limiting both longevity and productivity of the plants. Fusarium wilt is known to occur worldwide and has been described as a plant pathogen causing wilt, yellowing, and

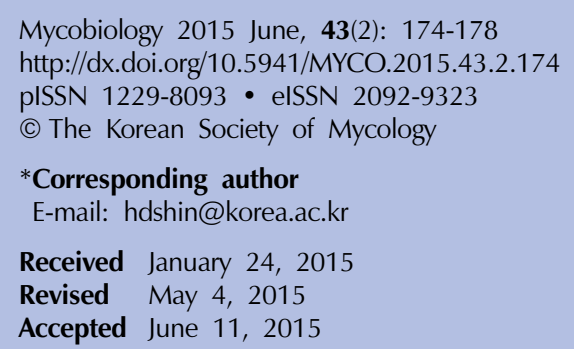

@ This is an Open Access article distributed under the terms of the Creative Commons Attribution Non-Commercial License (http:// creativecommons.org/licenses/by-nc/3.0/) which permits unrestricted non-commercial use, distribution, and reproduction in any medium, provided the original work is properly cited. death of plants [2].

In May 2013, hundreds of zucchini plants (cv. Taeyang) exhibited wilt symptoms as a result of an infection by a previously unknown fungus, with an incidence of 15 35\% (percentage of plants affected) in various plastic greenhouses that were surveyed in the Jeonju City of Korea. Initial symptoms started with chlorosis of leaves in April. The infected plants dropped off progressively upward, wilted, and eventually died in early June, causing severe economic loss (Fig. 1A). According to the farmers, the wilt disease appeared annually and developed during hot weather. As this infection clogged the vascular system, interfering with water movement, leaves turned pale green to yellow and root growth was inhibited. The infected stems developed necrosis and vascular discoloration internally. Internal vascular and cortical tissues of the plant crowns developed brown-to-orange-brown discoloration (Fig. 1B and 1C).

Isolation of the fungi and pathogenicity test. Samples of vegetation affected by the typical Fusarium wilt were collected from several areas by cutting the infected part of the stem from the zucchini plants. The infected tissues were surface-sterilized with a $1 \% \mathrm{NaOCl}$ solution for $1 \mathrm{~min}$ and rinsed 2 3 times with sterilized distilled water. After drying, we cultured the samples in $90-\mathrm{mm}$ petri dishes containing potato dextrose agar (Difco, Sparks, MD, USA) in the dark at $25^{\circ} \mathrm{C}$ for $1 \mathrm{wk}$. Voucher specimens were deposited in the Korea University Herbarium (KUS). Three isolates were obtained from vascular tissue of the infected plants. A representative isolate was placed in the Korean Agricultural Culture Collection (accession No. KACC47262) and used for the pathogenicity test and molecular analysis. 


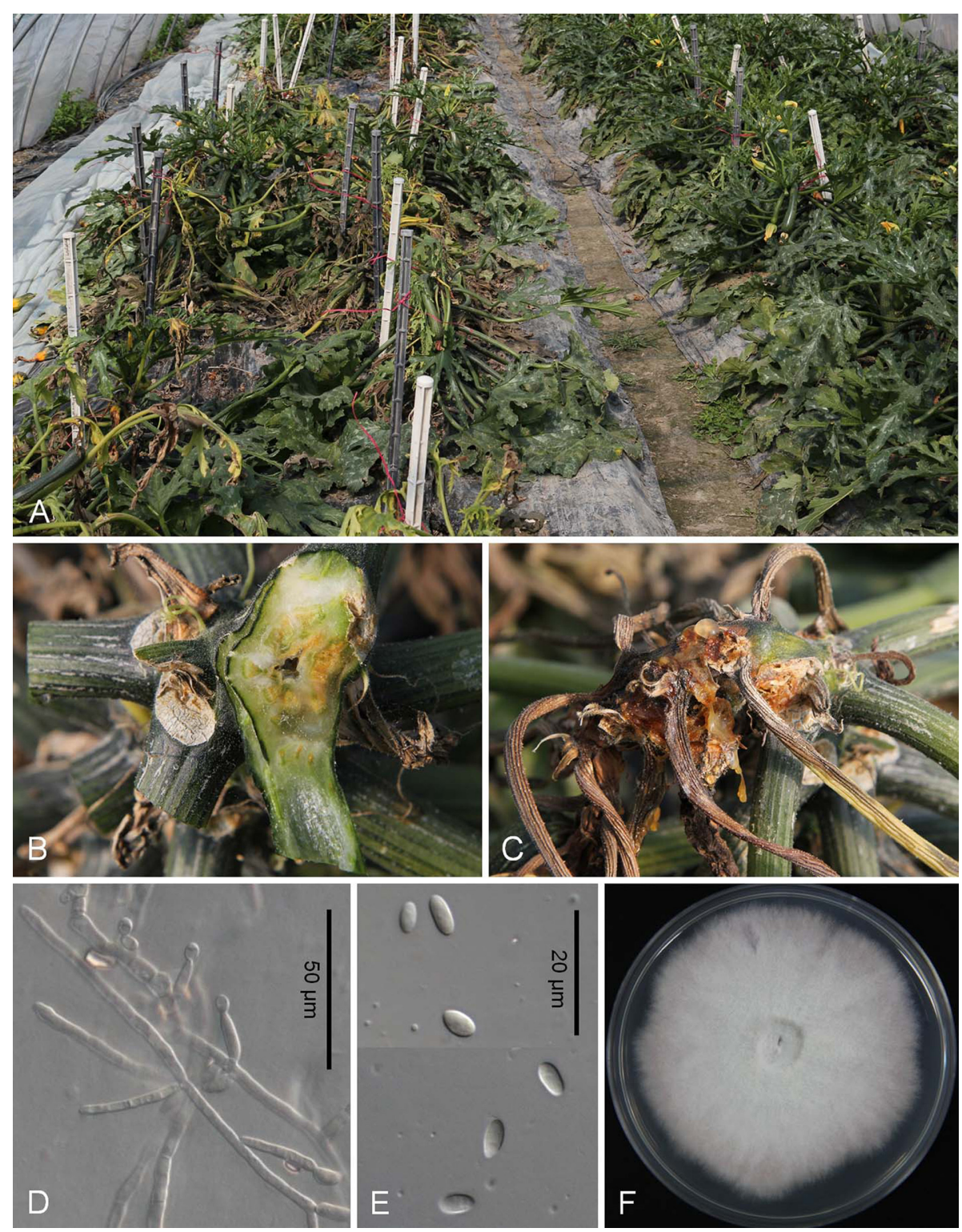

Fig. 1. Fusarium wilt caused by Fusarium oxysporum on zucchini (cv. Taeyang). A, The leaves and stems were infected, devastating the whole plants. Note severe infection on the left bed; B, The vascular system was blocked by the fungus; C, Dark streaks on an infected plant; D, Monophialides with microconidia on hypha; E, Microconidia; F, One-week-old colony of $F$. oxysporum growing on potato dextrose agar.

For the pathogenicity test, 10 zucchini seedlings (cv. Taeyang) were inoculated with the pathogen by dipping the roots into a conidial suspension $\left(2 \times 10^{5}\right.$ conidia $\left./ \mathrm{mL}\right)$. Another 10 seedlings serving as controls were processed similarly by dipping the roots into sterilized distilled water. The plants were retained in a humid chamber for the first $48 \mathrm{hr}$ and then maintained in the greenhouse with $80 \%$ relative humidity at $25 \pm 2{ }^{\circ} \mathrm{C}$. Three days after inoculation, wilt symptoms started to develop in the plants. This led to etiolation and vascular discoloration seven days post inoculation; these symptoms were identical to those originally observed in the plastic greenhouse. F. oxysporum was reisolated from the inoculated plants and it satisfied Koch's postulates. No symptoms were observed in the control plants.

Identification and characterization of $\boldsymbol{F}$. oxysporum. For morphological observation, a small piece of living tissue containing fungal structures was mounted in a drop of water. Bright-field and differential-interference contrast light microscopy (Zeiss AX10 microscope; Zeiss, Jena, Germany) were used to observe the specimen. Measurements of the fungal structures were performed at 200 1,000x magnification. At least 30 measurements were taken for each structure. Colonies on potato dextrose agar were $35 \mathrm{~mm}$ in diameter and pinkish-white; they felted with 
cottony and aerial mycelia within a week (Fig. 1F). In culture, microconidia formed abundantly on monophialides, while falcate macroconidia formed on (usually abundant) pale orange sporodochia. The macroconidia were short, falcate to almost straight, thin-walled, and usually threeseptate. Generally, abundant microconidia were formed in false-heads on short monophialides on the hyphae and were hyaline, smooth, oval to ellipsoidal, aseptate, oneseptate, or very rarely two-septate, slightly constricted at the septa with a size range of $4 \sim 11 \times 2.5 \sim 5.0 \mu \mathrm{m}$ (Fig. $1 \mathrm{D}$ and $1 \mathrm{E})$. Based on the morphological and culture characteristics, the fungus was identified as Fusarium oxysporum E. F. Sm. \& Swingle [3].

Differences in gene DNA sequence have previously been used to support morphology-based identification of Fusarium species. Further, phylogenetic analysis of DNA sequences has been used successfully to distinguish and evaluate the genetic relationship among closely related Fusarium species. The DNA sequences of the translation elongation factor $1 \alpha$ gene (TEF) have been widely used for identification of Fusarium species [4]. To further confirm our tentative identification based on morphological characteristics, fungal DNA was extracted using the DNeasy Plant Mini Kit (Qiagen Inc., Valencia, CA, USA). The complete internal transcribed spacer (ITS) region of ribosomal DNA (rDNA) and a partial sequence of TEF were amplified using primers ITS1/ITS4 [5] and EF-1/EF-2 [6], respectively. The amplicons were separated by $1.5 \%$ agarose gel electrophoresis, followed by purification using a PCR purification kit (Core-one; Core-Bio, Seoul, Korea). Reactions were sequenced using the BigDye Terminator Cycle Sequencing Kit (Applied Biosystems, Foster City, CA, USA) and analyzed on an ABI 3130 Automated DNA Sequencer (Applied Biosystems). The identity of the isolates was established by comparing their ITS and TEF sequences with those in the GenBank database (National Center for Biotechnology Information [NCBI] US National Institute of Health, Bethesda, MD, USA; http://www.ncbi.nlm.nih.gov/BLAST) and FUSARIUM ID (http://isolate.fusariumdb.org/blast.php), respectively. Phylogenetic analysis of ITS and TEF was conducted by neighbor-joining methods using MEGA version 6.0 [7], and the sequence distance was calculated based on the Tamura-Nei parameter model. Colletotrichum gloeosporioides (DQ084495) was used as an outgroup in the phylogenetic analysis. Bootstrap analysis, with 1,000 replications, was performed to determine the percentage support for each clade.

The ITS and TEF sequences from a representative isolate were deposited in GenBank with the accession numbers KF372590 (535 bp) and KF372592 (679 bp). A BLAST search of the ITS sequence in GenBank yielded 100\% nucleotide identity with the F. oxysporum (KC577181) sequence; in FUSARIUM ID [6], the TEF sequence was also identical (FD-01376). The phylogenetic trees generated using the

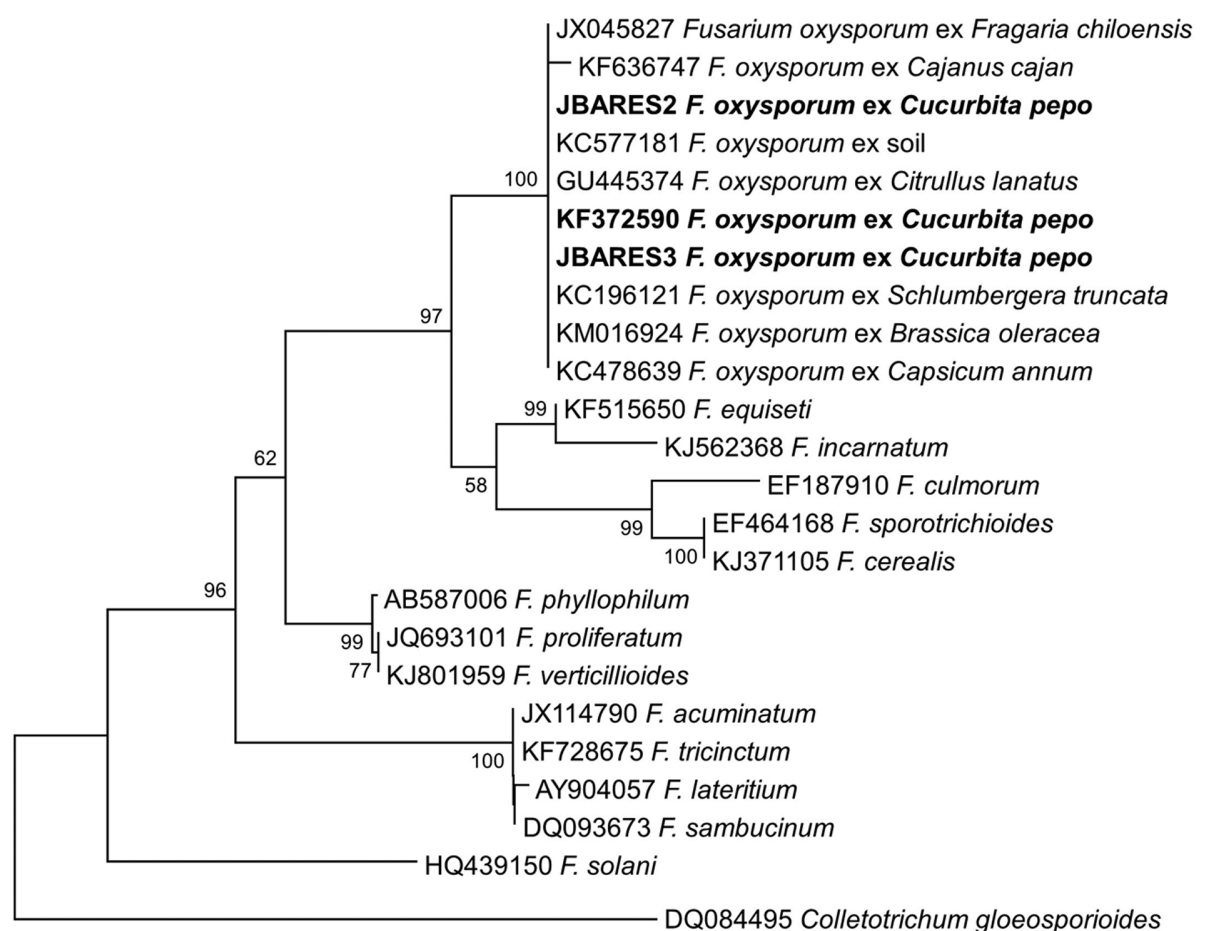

0.02

Fig. 2. Phylogenetic analysis by the neighbor-joining method comparing the sequence of the internal transcribed spacer ribosomal DNA (rDNA) region from Fusarium oxysporum with that of other Fusarium spp. obtained from GenBank. The numbers above the branches represent the bootstrap value. The fungal strains identified in this study are shown in boldface. 


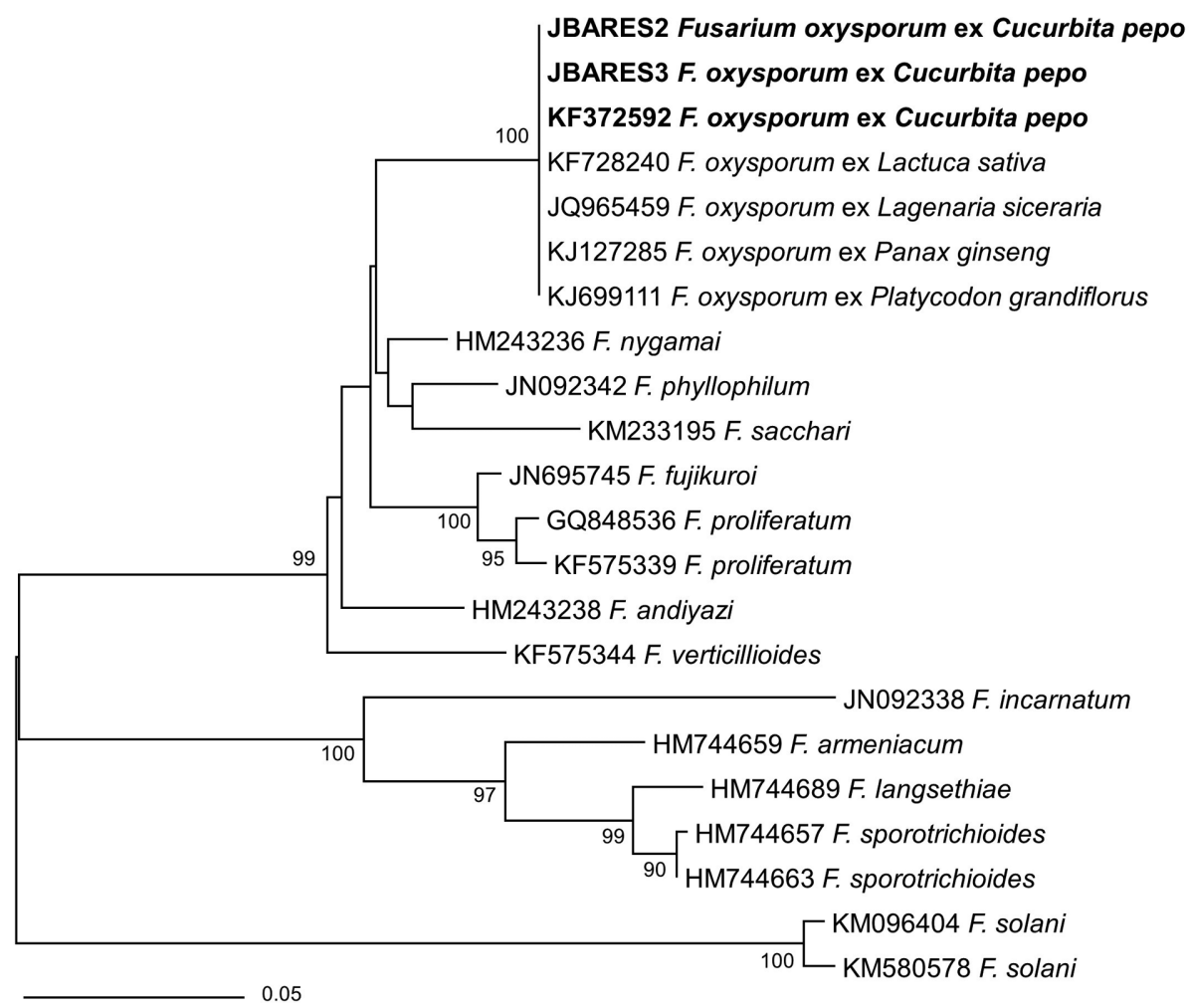

Fig. 3. Phylogenetic analysis using the neighbor-joining method comparing the sequence of translation elongation factor $1 a$ of Fusarium oxysporum with that of other Fusarium spp. obtained from GenBank. The numbers above the branches represent the bootstrap value. The fungal strains identified in this study are shown in boldface.

neighbor-joining method grouped the three zucchini isolates, including JABRES2 and JABRES3, in the same clade (Figs. 2 and 3$)$.

F. oxysporum-induced Fusarium wilt in C. pepo has been reported worldwide, such as in Mexico, Poland, and Greece [1]. Although there is a previous record of Fusarium sp. on Cucurbita sp. in Korea, but this record is ambiguous and requires verification [8]. To our knowledge, this is the first report of F. oxysporum causing Fusarium wilt on zucchini in Korea. Because this plant is of great economic importance, our results emphasize the need for disease management. In plastic greenhouses in Korea, zucchini are routinely farmed in reused soil. This practice is one potential reason for the relatively rapid spread of these pathogens, which can also be transmitted via infected weeds or survive on decaying plant material in the soil as saprotrophic mycelia and chlamydospores [9]. Currently, the best control strategies against Fusarium wilt in zucchini are crop rotation and soil disinfection. Careful drip irrigation management is also important in plastic greenhouse management. Hence, there is an urgent need to develop chemical and ecofriendly control methods for reducing the crop damage caused by these fungal pathogens.

\section{ACKNOWLEDGEMENTS}

This study was supported by the Cooperative Research
Program for Agricultural Science \& Technology Development (Project No. PJ0108252015) of the Rural Development Administration, Republic of Korea.

\section{REFERENCES}

1. Farr DF, Rossman AY. Fungal Databases. Bushland: Systematic Mycology and Microbiology Laboratory, Agricultural Research Service, US Department of Agriculture; [cited 2015 Mar 1]. Available from: http://nt.ars-grin.gov/fungaldatabases/.

2. Lee YS, Park CS. Fusarium species of Korea. Plant pathogens of Korea No. 5. Suwon: National Institute of Agricultural Science and Technology; 2001.

3. Nelson PE, Toussoun TA, Marasas WF. Fusarium species: an illustrated manual for identification. University Park: Pennsylvania State University Press; 1983. p. 142-5.

4. Hsuan HM, Salleh B, Zakaria L. Molecular identification of Fusarium species in Gibberella fujikuroi species complex from rice, sugarcane and maize from peninsular Malaysia. Int J Mol Sci 2011;12:6722-32.

5. White TJ, Bruns T, Lee S, Taylor J. Amplification and direct sequencing of fungal ribosomal RNA genes for phylogenetics. In: Innis MA, Gelfand DH, Sninski JJ, White TJ, editors. PCR protocols: a guide to methods and applications. San Diego: Academic Press; 1990. p. 315-22.

6. Geiser DM, del Mar Jimenez-Gasco M, Kang S, Makalowska I, Veeraraghavan N, Ward TJ, Zhang N, Kuldau GA, O'Donnell K. FUSARIUM-ID v. 1.0: a DNA sequence database 
for identifying Fusarium. Eur J Plant Pathol 2004;110:473-9.

7. Tamura K, Stecher G, Peterson D, Filipski A, Kumar S. MEGA6: Molecular Evolutionary Genetics Analysis version 6.0. Mol Biol Evol 2013;30:2725-9.

8. Korean Society of Plant Pathology. List of plant diseases in Korea. 5th ed. Suwon: Korean Society of Plant Pathology;
2009. p. 142-3.

9. Jamiolkowska, A, Wagner A, Sawicki K. Fungi colonizing roots of zucchini (Cucurbita pepo L. var. giromontina) plants and pathogenicity of Fusarium spp. to zucchini seedlings. Acta Agrobot 2011;64:73-8. 